\title{
Cone beam computed tomography in Endodontics
}

D’Addazio, P S S ; Carvalho, A C P ; Campos, C N ; Devito, K L ; Ȯzcan, M

DOI: https://doi.org/10.1111/iej.12600

Posted at the Zurich Open Repository and Archive, University of Zurich

ZORA URL: https://doi.org/10.5167/uzh-128019

Journal Article

Accepted Version

Originally published at:

D’Addazio, P S S; Carvalho, A C P; Campos, C N; Devito, K L; Özcan, M (2016). Cone beam computed tomography in Endodontics. International Endodontic Journal, 49(3):311-312.

DOI: https://doi.org/10.1111/iej.12600 


\section{Letter to the editor}

\section{D’Addazio PSS ${ }^{1}$, Carvalho ACP2 , Campos $\mathrm{CN}^{3}$, Devito $\mathrm{KL}^{3}$, Özcan $\mathbf{M}^{4}$.}

${ }^{1}$ Terezinha de Jesus Hospital and Maternity, College of Medical and Health Sciences - SUPREMA, Juiz d Fora, Brazil; ${ }^{2}$ Department of Radiology, Medical School, Rio de Janeiro Federal University, Rio de Janeirc Brazil; ${ }^{3}$ Department of Dental Clinic, Dental School, Juiz de Fora Federal University, Bairro, Juiz de Fora Brazil; ${ }^{4}$ University of Zurich, Dental Materials Unit, Center for Dental and Oral Medicine, Clinic for Fixed an Removable Prosthodontics and Dental Materials Science, Zurich, Switzerland.

\section{Dear Editor,}

We would like to congratulate the authors on the review article entitled "Cone beam computed tomograph in Endodontics - a review". ${ }^{5}$ The literature review presents a very thorough summary of the impact an application of cone beam computed tomography (CBCT) in diagnostic imaging in the field of Endodontics The importance of the subject is increasing for the dental community as stressed in the article. Yet, $w$ would like to highlight some related aspects of this technology as an adjunct to the discussion that was $\mathrm{nc}$ enclosed in the article.

Regarding the specific application of CBCT in the diagnosis of vertical root fractures (VRF), we agree wit the authors that in principle the $\mathrm{CBCT}$ could not be recommended for their diagnosis at this stage. Althoug some in vivo and ex vivo studies, and clinical case reports underline the superiority of CBCT compared wit periapical radiographs on the diagnosis of root fractures, the diagnostic confirmation requires a keen sens of the clinical professional. Moreover, information obtained during the interview, clinical examination, an especially periodontal probing, are crucial parameters that need to be taken into account during evaluatio of the derived information. The possibility of a false positive diagnosis of the observer especially in th presence of metal cast post should also be contemplated that may yield to an incorrect therapy. ${ }^{1}$ Against th improvements in the CBCT for dental use, the available devices present resolutions still far below th resolution of computed-microtomography (CMCT), where the latter enables the operator to view changes $i$ the microscopic structure of the teeth. Unfortunately, such technologies are available only to study sma objects at laboratory settings. ${ }^{2}$ The possibility of obtaining near resolutions of CMCT coupled with the CBC may increase accuracy in the diagnosis of VRFs in the near future. ${ }^{4}$ Thus, the advances in the neI generations of CT scanners, using technologies with improved resolution ratio/radiation dose, woul possibly bring a breakthrough in diagnosis of VRFs which is not there yet. Until then, guidelines fc calibration of the operators could have been given in this article. 
The review also emphasizes the training in CBCT in terms of knowledge of the clinician on th characteristics of endodontic complications, experience in the acquisition, interpretation and awareness 0 the limitations of the CBCT images. The problem is that general practitioners and even endodontist themselves, most frequently do not participate in setting the parameters of image acquisition an elaboration of diagnosis but instead delegate this to the maxillofacial radiologists. Eventually, maxillofacis radiologists interpret solely the image or when available, combine the interpretation with the informatio provided by the clinician. In fact, one advantage with the CBCT images is that the clinician can view ther on his/her own personal computer. However, then it becomes very imperative to use advanced softwar programs, providing high quality images. The availability of advanced tools, such as specific filters, softwar programs used at Radiology departments should be ensured that may allow better visualization of th lesions. The level of training and experience of the examiner may influence the identification of cariou lesions on radiographs, and this statement holds also true for the diagnosis of endodontic deviations whe CBCT is used. $^{3}$ Briefly, we contemplate that domain of computers and related tools, experience an calibration of the operator with computers, delegation of interpretation to maxillofacial radiologists are ke elements to exploit the CBCT technology for endodontic diagnostics at best, which were not mentioned $\mathrm{i}$ the Discussion of this review article.

\section{References:}

1- Bueno MR, Estrela C, Figueiredo JAP, Azevedo BC. Map-reading strategy to diagnose roc perforations near metallic intracanal posts by using cone beam computed tomography. Journal c Endodontics, 37, 85-90, 2011.

2- Hannig C, Dullin C, Hülsmann M, Heidrich G. Three-dimensional, non-destructive visualization c vertical root fractures using flat panel volume detector computer tomography: an ex vivo in vitro case repor International Endodontic Journal, 38, 904-13, 2005.

3- Héllen-Halme K, Petersson GH. Influence of education level and experience on detection c approximal caries in digital dental radiographs. An in vitro study. Swedish Dental Journal, 34, 63-9, 2010.

4- $\quad$ Huang C-C, Chang Y-C, Chuang M-C, Lin H-J, Tsai Y-L, Chang S-H, Chen J-C, Jeng J-H. Analysi of the width of vertical root fracture in endodontically treated teeth by 2 micro-computed tomograph systems. Journal of Endodontics, 40, 698-702, 2014.

5- $\quad$ Patel S, Durack C, Abella F, Shemesh H, Roig R, Lemberg K. Cone beam computed tomography i Endodontics - a review. International Endodontic Journal, 48, 3-15, 2015. 